\title{
Fit and Flexible: The Fitness Industry, Personal Trainers and Emotional Service Labor
}

\author{
Jennifer Smith Maguire \\ The Graduate Center, City University of New York
}

The contemporary United States fitness industry, in conjunction with the medical endorsement of exercise and the marketing of lifestyle consumption, has made possible the emergence and rapid growth of health and fitness services. This paper brings together the sociological fields of work, consumption, and physical culture, suggesting how the structure and organization of personal training impacts upon how fitness is sold. Drawing from interviews with personal trainers, the occupation is discussed as a combination of frontline service work, emotional labor, and flexible work strategies, resulting in a variety of job roles: the representation of the fitness club, the brokering of clients' consumer relationships with the fitness industry, the motivation of clients through service relationships, and the entrepreneurial cultivation of a client base and semi-professional authority.

Aux États-Unis, l'industrie contemporaine de la condition physique a profité de l'appui médical à l'exercice et du marketing de la consommation reliée au style de vie pour permettre l'émergence et la croissance rapide de services dans le domaine de la santé et de la condition physique. Cet article regroupe les champs sociologiques du travail, de la consommation et de la culture physique pour suggérer comment la structure et l'organisation de l'entraînement personnalisé influence la façon dont la condition physique est vendue. A partir d'entrevues avec des entraîneurs personnels, leur occupation est discutée en tant que combinaison de travail de service aux clients, de travail émotionnel et de stratégies de travail flexibles. Cette occupation résulte en une variété de rôles: la représentation du centre de conditionnement physique, le courtage des relations entre le client-consommateur et l'industrie de la condition physique, la motivation des clients par le biais des relations de service et la culture d'une clientèle ainsi que d'une autorité semi-professionnelle.

There is perhaps no cultural theme more emblematic of our current dual obsessions with health and appearance than that of fitness. While its modern roots extend back to the physical culture and health reforms of the 19th century, fitness as we know it today is far and away a commercial venture. Even when the ostensible goal is health promotion rather than image improvement, fitness tends to take place in and through the consumer marketplace. Since the early 1970s, the pursuit of fitness has developed into a multi-billion dollar industry in the United States, spanning the health food, exercise equipment, instructional video, and health club industries. This paper examines the occupation of personal training, an innovation of the fitness industry of the past 10 years. Paid to design and facilitate individual

The author is in the Ph.D. Program in Sociology at The Graduate Center, City University of New York, New York, NY 10016. An earlier discussion of this research was presented at the North American Society for the Sociology of Sport meeting in Las Vegas, November 1998. 
fitness programs on a one-to-one basis, personal trainers have become a standard feature in many health clubs. ${ }^{1}$ While a range of fees accommodate an ever-growing number of clients, personal trainer services remain exclusive enough to serve as a status symbol for its many consumers. With the standardization of training certifications and career strategies, and an increasingly educated public demanding more individualized and reliable health-and-fitness services, the occupation of personal training has become a key feature in the selling of fitness.

The paper's objectives oscillate between two levels. Most broadly, the paper examines the fitness industry, its connections to consumer culture, and the import of emotional service work to both, in an attempt to understand the structural organization of the culture of fitness in the U.S. Scholarly attention has generally overlooked the "production" side of contemporary fitness, focusing (albeit fruitfully) on the consumption of body culture through the subjective experiences and motivations of participants and the manipulation of consumer anxieties to promote the use of health and beauty products (Bordo, 1993; Glassner, 1989; Maguire \& Mansfield, 1998; White, Young, \& Gillett, 1995). Apart from attempts to link fitness into wide-ranging political economic trends (Cole, 2000; Featherstone, 1982; Ingham, 1985; Rader, 1997; Sage, 1998), the study of contemporary fitness remains largely isolated within the domain of physical culture, disconnected from its context in the larger network of consumer goods and services, and health care and health promotion industries. Thus, this paper brings together the sociological fields of work and consumption within the study of physical culture in an attempt to broaden our understanding of the forces shaping the culture of fitness, from the diffuse strategies of lifestyle marketing to the direct interaction between fitness service provider and client.

Embedded within and illustrative of the broader discussion of the fitness industry is the paper's more limited objective-an analysis of the occupation of personal training. Using both fitness industry information and data from interviews with current and former trainers, ${ }^{2}$ the study traces the contours of the occupation within the context of the service industry and the overall changes to the structure and organization of work. Personal training, among a number of rapidly growing health and fitness services, ${ }^{3}$ is an example of the kind of service work responsible for articulating the deep connections between the fitness industry and consumer culture. In connecting the fitness culture to the work of fitness, the paper addresses a void in the social scientific treatment of contemporary body cultures. With few exceptions (Lloyd, 1996; Young, 1991, 1993), sociologists have overlooked the role of the organization and structure of work in the shaping of physical cultures. Personal training is one occupation directly involved in the production of the culture of fitness, yet despite their rapidly growing ranks, the scholarly awareness of personal training (Rapp, Campbell, Thompson, \& Terbizan, 1999) lags far behind that contained within career guides and consumer reports (O'Brien, 1997; Roberts, 1996).

Personal training falls within a category of service work that defies many of the traditional definitions of such work as deskilled or emotionally alienating (Braverman, 1974; Hochschild, 1983; Smith, 1994; Wharton, 1993, 1999). The overlapping concerns of service work, emotional labor; and flexibility frame the structure and organization of personal training, shaping the varying degrees of autonomy and constraint, modes of establishing authority, and broader implications of the one-on-one service interaction in the fitness club and larger fitness 
andard

-grow-

o serve

raining

emand-

ation of

e paper

import

1 orga-

y over-

itfully)

d moti-

lote the

uire \&

ink fit-

1982 ;

iess re-

rom its

are and

1 fields

impt to

om the

fitness

fitness

ition of

1 inter-

e occu-

; to the

rapidly

e work

try and

e paper

sltures.

e over-

hysical

tion of

aware-

lags far

, 1997;

lany of enating 9). The me the rees of nplicafitness

industry. While the paper focuses on the fitness industry in the United States, the findings will be relevant to the fitness industries of other Western consumer cultures; both the United Kingdom and Canada, for example, have organizations that represent and seek to enhance the profession of personal training. ${ }^{4}$ Personal training is one node in a larger network of personal services, connecting narrow fitness activities to far-reaching middle-class patterns of lifestyle consumption. Fitness is not simply a matter of working on one's body shape or health, but part of a larger set of consumer activities and health promotion strategies making claims upon individual identity.

The paper proceeds with a discussion of the rise of the fitness industry and its links to 19th century reform movements and early 20th century appearance industries. The fitness industry's boom in the 1970s cannot be separated fromchanges to the service economy, consumer culture, and the associated transformation of the structure and organization of work. These related changes in the consumer fitness culture, and the structure of work, set the stage for the occupation of personal training, with its combined elements of service work, emotional labor, and flexibility.

\section{Fitness in Contemporary Consumer Culture}

To paraphrase Bourdieu (1990), one cannot study the consumption of personal training services without studying the consumption of fitness culture in general. In other words, personal training must be located within a consumer culture in which body maintenance and improvement have been elevated to the status of ideal pursuits. This is not to suggest that consumer culture invented the notion of body maintenance. The practice of manipulating the body through diet and exercise, for example, was popular with the North American middle classes by the middle of the 19th century (Bordo, 1993; Green, 1986; Gruneau, 1997; Schwartz, 1986). Like so much of what we take to be emblematic of our time, fitness has a much longer history than the recent rise of health clubs and personal trainers might suggest.

Of particular note in the development of fitness in the U.S. is the long-term shift in its underlying rationale from the scale of social welfare to individual improvement. In the 19 th century, exercise was encouraged as a social program, a panacea for the physical and psychological ailments associated with urbanization and industrialization: disease, injury, and moral corruption for the poor and working classes; sedentariness, stress, and effeminacy for the middle classes (Green, 1986; Whorton, 1982). As a means to a strong, healthy, and moral society, physical exercise was the linchpin in countless health and moral reform movements, and their accompanying-though limited-commercial ventures. Apart from their impact on health and levels of physical activity, health reformers and physical culture entrepreneurs helped institutionalize exercise as part of middle-class life (Riess, 1989). In doing so, they endorsed two significant principles: On the one hand, they supported the long-standing belief that health is a matter of personal responsibility; that is, nature was assumed to be a good force, and the unnatural state of ill health was thus a sign of personal failing (Whorton, 1982). On the other hand, these ventures promoted the body as a marker of social status (Bordo, 1993; Bourdieu, 1984; Featherstone, 1982; Schwartz, 1986). Not only did an ill, or illkept, body denote personal failing, but low social status, weak moral character, 
and poor social mobility as well. Thus, the unintended consequences of the social rationale for fitness in the 19 th century were the promotion of personal responsibility for the state of one's body and health, and the equation of bodily appearance with personal worth: the two foundations for an individual rationale of fitness.

Building on the groundwork laid by the earlier reformers, the early 20th century witnessed a massive explosion in appearance industries: goods, services, and advertising targeting the inadequacies and improvement of bodily appearances (Ewen, 1976; Peiss, 1998). For example, cosmetic and dieting industries in the 1920s turned exercise from a means to a strong society to a means to a better appearance (Peiss, 1998; Stearns, 1997). While the individualistic goals of exercise remained inherently social —one needed to look better to compete in the marketplace, to "fit" into society - the scale of the purpose of fitness diminished from the social to the individual (Falk, 1994; Mrozek, 1989). Also driving the development of these appearance industries was the growing service industry, generating increasing pressure, upon the middle classes in particular, to develop personal appearance as a means of successfully participating in the marketplace. Over the 20th century, the moral imperative, social duty, and economic necessity of maintaining a particular body shape have only escalated as the social world becomes increasingly dense and impersonal, careers become more bureaucratized, and social relations take place increasingly through judgements based on appearances and impressions (Bourdieu, 1984; Featherstone, 1982; Susman, 1979; Wernick, 1991; White, Young \& Gillett, 1995).

A commercial fitness industry on par with the scope and scale of the dieting and cosmetic industries did not come to the fore until the early 1970s, a seemingly belated beginning given the enormous emphasis on bodily appearance in the consumer culture of the early 20th century and existing limited commercial fitness ventures (Green, 1986; Mrozek, 1989). Popular trends in jogging, tennis, and aerobics were shaped by and gave shape to the rising sales of athletic shoes (Vanderbilt, 1998), health foods (Whorton, 1982), and memberships in exercise studios and health clubs (Kaye, 1977; Taylor, 1969, 1972). In the case of New York City, the number of fitness clubs rose from 10 to 43 between 1973 and 1983 (Goldman \& Kennedy, 1983); today the number exceeds 200 . While the contemporary incarnation of fitness differs from its 19th century predecessors, the same themes are at work in the modern fitness industry's boom in the 1970 s and its continuing success: the principles of the personal responsibility for health and the social necessity of appearances.

In the case of health, the rise of the fitness industry is associated with a changing context of disease. In the latter part of the 20 th century, in the wake of the advent of antibiotics and a rising overall standard of living, the killers of the 19 th century - cholera and tuberculosis-have been replaced by such "lifestyle" or "risk" ailments as heart disease and cancer. Although resistant to drug-based "cures," medical research continues to demonstrate the preventive role of exercise and other lifestyle factors for these newly dominant diseases. Thus, where once health advocates stressed matters of water and air quality, today's leading health indicators are physical activity; obesity; and tobacco, drug, and alcohol abuse (Office of Disease Prevention and Health Promotion, 2000). The scientific substantiation of exercise as a means for individuals to reduce personal health risk has meant that the medical establishment has lent much credence to the fitness industry. Moreover, the fitness industry owes much to the changing fortunes and crises of 
Ie social esponsiearance ness.

tly 20 th ervices, arances $s$ in the a better of exerhe mared from eveloplerating mal apIver the $f$ mainecomes and soarances 'ernick, dieting mingly he confitness d aeroderbilt, ios and ity, the man \& carna$s$ are at ig sucneceswith a rake of of the estyle" -based kercise e once health se (Oftantiameant dustry. ises of

the health care system (Drury, 1983; Sage, 1998). Since the 1970s, the solution to the high cost of health care increasingly has been the promotion of preventive health care, particularly with respect to exercise, diet, stress, smoking, and drinking (Crawford, 1980; Ingham, 1985). Thus, the economic rationality of exercise as a way for the individual to decrease the health care system's burden lent both urgency and institutional support to the commercial development of fitness in the 1970 s. Buoyed by the corporate sponsorship of wellness programs designed to increase productivity while decreasing health care claims (Gibson, 1974; Gilmore, 1977), and by the general population's growing expectations for longevity and health (Glassner, 1989; Rader, 1997), the fitness industry continues the long-standing trend of placing the responsibility for health squarely on the shoulders of individuals.

With respect to appearances, the rise of the fitness industry is interconnected with an intensified consumer culture following the 1960s. As groups-particularly women and minorities-challenged the "mass" to which mass marketing attempted to reduce them, consumer culture became arguably more fragmented and inclusive. However, if consumer industries attempted to reflect the emerging identity politics, they were no less commercial or appearance-based. For example, the production of make-up may now include a wider range of skin colors, but the social stress upon improving one's appearance is no less distinct (Peiss, 1998). Likewise, exercise and fitness are no longer matters solely for athletes, the military, and health practitioners. As June, ${ }^{5}$ a personal trainer, reflected, fitness has become an everyday concern-if not an everyday activity:

Everyone is into working out now. It's not a YUPPIE or BUPPIE ${ }^{6}$ thing anymore. Normal people are doing it. The cable guy is working out. The secretary is working out. The average person is slotting it into their time schedule and budget. In the last two or three years, the atmosphere has really changed. It used to be that people would say, "Oh, you work out?" But now everyone does. A big part of it is music videos, I think. You see all these homeboys in great shape. And the girls too, in videos and advertising. And people want that body. There's also the fact that this generation has grown up exercising. Their moms and dads were running as they were growing up, so it's normalized.

As June's comment suggests, the growth of a culture of fitness has required both the dissemination of fitness awareness and the intensification of the pressure to be fit, if not an actual democratization of fitness club memberships. ${ }^{7}$ The tension between inclusion and exclusion has meant that a democratization of muscles is accompanied by a further stigmatization of fat, or otherwise unfit, bodies. The historically male ideal of an athletic, muscular body now extends increasingly to women. However, ideal body shapes and appearances remain exclusively within tight, toned terms; the social acceptance of overweight, older, or extremely muscled bodies remains marginal (Balsamo, 1994; MacNeill, 1994; Schwartz, 1986; Stearns, 1997).

As consumer culture diversifies to reflect the individuality of consumers, it does so within a logic of conformity to consumerism, however fragmented. That is, advertising, marketing, product development, and promotion all encourage us to express our individuality through consumer products and services. Rather than fit into a mass consumer profile, we are urged to create our own lifestyle and 
identity through consumption. For example, not only do brands of athletic shoes compete for our attention, but different models within each brand profess to better express our hopes and dreams, be they for speed, peace, confidence, or escape. The fitness industry's increasing array of goods and services can both enrich and contradict the meanings of other lifestyle- and identity-enhancing goods and services, from manicures and facials to organic food, haute couture, and massage therapy. It is not that all of these elements are equally interchangeable, but that in selecting and combining, we create and express ourselves as choosing, self-controlled individuals. The equation of freedom with product choice, and of consumer lifestyle with identity, have been the overriding messages of advertising since the late 1960s, which has endorsed self-expression, for those who can afford it, through consumption (Featherstone, 1991; Slater, 1997).

The message of lifestyle consumption has been further entrenched by the growing ranks of personal service providers, who respond to and foster a demand for services that reflect the individuality of customers. Indeed, service providers are capable of individualizing their services-and catering to the individuality of consumers-to a degree far greater than niche marketing and product differentiation; the shoe salesperson, for example, interacts with the customer on a more personal, spontaneous level than the shoe and its associated advertising messages. Service providers reinforce the equation of consumption with identity expression by tailoring the experience of products, and consumption itself, to the individual consumer. However, it does not follow that lifestyle consumption is merely a question of manipulated consumer desire. Consumers' desires for distinction, authenticity, and individuality are not simply the result of manipulation by advertisers and marketers, but are also legacies of the dehumanizing forces of scientific management and bureaucratization. Such desires have given rise to a market for precisely differentiated products and personal services, a minute tailoring of mass goods and services to reflect one's consumption-based individuality.

The medical establishment's endorsement of fitness is thus accompanied by the culture industry's conscription of fitness into the service of lifestyle consumption. Not surprisingly, a British study in the late 1970s found that fitness and a good diet were most effectively promoted by their cosmetic rewards (Featherstone, 1982, p. 25). Fitness activities, fitness equipment, and fit bodies are all touted as components of a particular way of life, an expression of personal identity and social status, and an appropriate arena of creativity and control in an increasingly bureaucratized, out-of-control social world. This logic of lifestyle consumption further obscures socioeconomic inequalities behind the veil of aesthetics; inequalities in appearance stand in for structural inequalities, perpetuating the delusion that the solution to disparities in education, income, or health lies simply in selfimprovement (Bordo, 1993; Ewen, 1999; Featherstone, 1991; Ingham, 1985). The fitness industry and medical establishment may promote fit bodies, but they also marginalize those that are unfit.

Ironically, one effect the booming industry has not had is an appreciably fitter general population. Although less affluent and less educated individuals are more apt to be physically inactive, the middle classes-the target market for the fitness industry - are far from immune to the dangers of obesity and inactivity (Office of Disease Prevention and Health Promotion, 2000). The seemingly paradoxical perpetuation of an unfit population in the face of growing fitness club membership is, in part, explained by the role of health in the fitness industry. Health 
ic shoes

to better

escape.

rich and

and ser-

nassage

that in

elf-con-

insumer

ince the

through

I by the

demand

oviders

Iality of

erentia-

a more

sssages.

ression

lividual

a ques-

authen-

ertisers

ic man-

for pre-

of mass

nied by

asump-

$s$ and $a$

rstone,

uted as

ity and

asingly

mption

equali-

slusion

in self-

5). The

ey also

ciably

als are

for the

ctivity

y para-

is club

Health

has been mobilized as both the alibi and the sanction for appearance management. The fitness industry has flourished since the 1970 s because it is not merely a question of preventive health care, nor simply a matter of exercise, but is one part of larger lifestyle projects of the middle classes. Thus, fitness has become such big business in the past 30 years because it is first and foremost a consumer-not a medical-industry, following the same organizing principles and involved in the same lifestyle projects as other consumer industries, such as fashion and beauty. To put it simply, fitness has less to do with body-building than it does with identity-building (Donnelly \& Young, 1988; Falk, 1994; Fine, 1987). The success of the fitness industry, then, rests with its practitioners and promoters interweaving the various goods and services with customers' identity projects; the importance of personal service providers in catering to and satisfying the individuality of customers must not be underestimated.

\section{Service Work, Emotional Labor, and Flexibility}

Unlike the early 20th century's consumer culture, services now eclipse goods in the generation of businesses and in the creation of jobs. This change in the organization of work, from creating things to creating interactions, produces the possibility for new occupations and new ways of facilitating lifestyle consumption. To understand the phenomenon of personal training, then, one must appreciate the organization and structure of work within the service industry, the single biggest sector of the contemporary U.S. economy (Bureau of Labor Statistics, 2000a).

With fewer technical skill requirements than the manufacturing jobs they have eclipsed, service occupations are regarded as part of a process of de-skilling that accompanies the historical development of capitalism. As workers require fewer skills and make fewer decisions, they find less meaning in a work life increasingly characterized by anomie, boredom, and stress (Braverman, 1974). In general, service sector occupations are characterized by faster than average growth, lower salaries, lower rates of unionization, and higher percentages of women, young people, and minorities (Watkins, 1993, p. 42). These generalizations, however, are somewhat misleading; service work is not an undifferentiated mass. Personal training both fits and conflicts with the general sketch of service jobs; it is characterized by non-unionized, younger employees, but by neither a predominance of women and minorities, nor low wages. ${ }^{8}$ In general, service occupations comprise a spectrum of jobs ranging in degrees of skill, autonomy, prestige, and remuneration.

Following the post-1960s expansion of the service economy, consumer industries--fitness included-have placed a growing emphasis on frontline service, the direct interaction between the customer and the service provider (Pine \& Gilmore, 1998; Watkins, 1993; Wharton, 1993). Because of its emphasis upon customer interaction, frontline service is fundamentally concerned with relational skills and appearance management. For personal trainers, for example, non-traditional skills include such qualities as body shape and attitude. Bill, a manager of programs at a fitness club and former personal trainer, commented upon the various and unexpected skills required for occupational success:

To be seen working out in work out gear is the best way to flaunt your package. The number one skill [for personal trainers] is charisma, but there's 
more to it. The uniform doesn't flaunt your physique. You have to teach trainers to sell and market themselves, to be entrepreneurs for themselves. They have to learn how to work the floor and how to work clients. It's about making an impression, not a hard sell.

Thus, personal trainers depend on their personalities and appearance, regardless of their certifications and technical skills. In general, a frontline service provider's skills, body type, appearance, and communication abilities are often more important to a customer's feelings of satisfaction than traditional factors such as price or availability (Solomon, 1998), or the service worker's technical skills and qualifications.

Frontline service is particularly relevant when the quality of customer interaction becomes the distinguishing feature between largely indistinguishable goods. In the case of the fitness club industry, consolidation of clubs and the expansion of local, regional, and national chains have meant that prospective members choose between clubs offering much the same equipment, classes, and amenities (Pristin, 1998). The fitness club industry is highly competitive and has long suffered from a poor rate of member retention. As the vast majority of revenue comes from member dues, it is of great importance that members remain satisfied and loyal (Waters, 2000). As such, the frontline service delivered by personal trainers (as well as by other instructors and sales and reception staff) becomes a primary means of attracting and retaining members.

The non-technical skills or qualities required of frontline service workers are elements of emotional labor. Hochschild's analysis of emotional labor (1983) explores how workers must manage their own feelings in order to create a specific bodily display (such as a welcoming, smiling persona) that will then evoke an appropriate emotional response in another person (typically the customer). Thus, the provision of services is insufficient in itself; services must also be provided in a certain style. While we may associate this form of work most readily with service occupations, it is an increasingly important element to a range of occupations that, to varying degrees, are concerned with and accountable for the emotional responses of customers and clients, such as human resource administrators, university professors, talk show hosts, and physicians (Hochschild, 1983, p. 237). As such, the occupational expectations and constraints faced by personal trainers shed light upon the emotional labor content of other occupations.

Frontline service workers deliver particular information to the consumer while providing an impression of the company and a connection-an invitation-to other consumption opportunities. That is, the purpose of services lies not just with the immediate customer interaction, but also with the representation of the employer or company, and the implication of the consumer, via the service provider, in the broader web of consumer goods and services. In light of the different scales of expectations-those of the customer, company, and consumer industry-frontline service workers occupy "boundary-spanning" positions that require a negotiation of the diverse and sometimes conflicting expectations. Service providers must rely on emotional labor strategies in place of any formal authority over customers in their attempts to please customers within the parameters, and in conjunction with the objectives, set by the company and industry (Wharton, 1993, 1999). Personal trainers, for example, lack the authority of a doctor or physical therapist and thus must cultivate an appropriate persona, which generates its own authority and is 
to teach

mselves.

t's about

rdless of ovider's e imporprice or ills and

er intere goods. nsion of ; choose (Pristin, ed from member Waters, Ill as by is of at-

workers : (1983) specific roke an ). Thus, rided in ith serpations lotional irs, uni37). As :rs shed

Ir while to other vith the oployer ; in the ales of ontline tiation ust rely ners in on with zrsonal ad thus and is

further legitimated through professionalization strategies such as certification. Through the cultivation of authority, based on professional and relational skills, personal trainers motivate their clients to follow their workout instructions, while at the same time creating a satisfying impression of the gym to ensure member loyalty. In effect, frontline service involves two roles, one in managing the customer, and the second in representing the company; the challenges and constraints of one role can often be difficult to reconcile with the other.

In general, then, the experience of shopping, buying, and using has become as important as the product itself, and the service provider, the personal trainer, is a crucial element for the satisfaction of the customer and his/her sense of identity, and for the overall success of the business. As such, it is hardly surprising that businesses are increasingly interested in controlling the quality of service, a highly variable factor given its inherently unpredictable human component. Employers may seek to ensure that company objectives are met by managing service providers through such techniques as employee screening and training, service scripts, and routinized interaction patterns (Leidner, 1999). However, such top-down management of relational skills poses the threats of job dissatisfaction and exhaustion for emotional laborers (Hochschild, 1983; Leidner, 1999; Steinberg \& Figart, 1999; Wharton, 1993, 1999). In general, strategies that constrain the worker's realm of discretionary judgement and creativity-be it in manufacturing, service, or elsewhere-contribute to such ill effects as estrangement from one's own emotions, feelings of inauthenticity, withdrawal, alienation, and burn out. Thus, emotional exhaustion is not endemic to emotional labor, but is the result of a loss of job autonomy. Indeed, emotional labor, under the right circumstances of employee autonomy, can offer different kinds of job rewards and higher degrees of job satisfaction than other kinds of work (Wharton, 1993).

If relational skills suffer the threat of de-skilling, they also complicate the notion that a service economy necessarily involves a loss of workers' skills and decision making. The case of frontline service work suggests that, for some occupations, technical skills are necessary but not sufficient occupational qualifications; there is a shift, rather than an overall decline, from task-based to relational skills, from certifications to charisma. What is more, there is the implication of a change in the gendered definition of skills. The increasing importance of emotional labor suggests that a range of skills, aptitudes, and emotions (such as nurturing, encouraging, and consoling), historically associated with women and women's jobs, are becoming a central feature of work for both men and women (Steinberg \& Figart, 1999). This is not to suggest that relational skills have parity with technical skills. There remains much ambiguity surrounding which skills are the basis for pay. In the case of personal trainers, the set of required skills ranges from technical knowledge and certifications, which are explicitly required and rewarded, to "people" skills, which are implicitly required and rewarded. In other words, with more certifications, personal trainers are able to charge more per hour, but without good interpersonal skills, they fail to retain clients. Thus, relational skills continue to be undervalued in a strictly economic sense, even if they outweigh technical or task-based skills in overall job success.

For service work, and for emotional labor in particular, job autonomy is the hinge on which skill retention and job satisfaction hang. For service businesses, the desire to control the quality of service interactions must be balanced with the potential ill effects upon service providers and the subsequent compromise of service 
quality. If businesses insist on overmanaging their frontline service providers, they risk rendering service interactions so contrived and inauthentic that customer satisfaction suffers, as well as alienating employees (Leidner, 19). The dilemma of balancing quality control with employee autonomy and productions relations and scienbalancing quality control with employee auto of industrial work relations and scien-
tific management prompted by the disadvantages of de-skilling and worker dissatisfaction.

The notion of workplace flexibility was given a tone of urgency by the global challenges in the 1970s to North America's dominance in production and corporate profitability (Smith, 1997). In an attempt to better motivate firms began experiincreasing the ability to change product lines quick 1984). Theoretically, flexibimenting with flexible specialization (Piore \& Sabel, 198 ) ity takes one of two forms. "Enabling" or "functional flexil and skill advancement to core workers, who are allowed greater self-conce (Smith, 1994, 1997). order to achieve a more flexible, adaptable work force (Smilt, 194,1997 ). Perpation if they have a range of training specializaterly, and the physically challenged. Flexible specialization allows trainers to charge more for their services while attracting a wider range of clients, while enabling clubs to market themselves as more adaptable to members" changing needs. In contrast, "restrictive" or "numerical" flexibility refers to the short-term or part-time work force whose size can be quickly tailored to meet the market demands, at the cost of de-skilling and unstable employment (Smith, 1994, 1997). Fitness clubs have a numing sessions flexible personal training labor force, as customer dem. Personal trainers may betermines the size of the paid labor force on any day. Personal trainers may be employed by a fitness club but are not guaranteed a stable income largely responsible for are contingent upon client appointments, which they are lark is particularly evident soliciting and arranging. The contingent nature of the work and March, when persoliciting and arranging. The contingent nature of the club use in January and March, when per-
during the annual peaks in U.S. fitness clu short-
sonal trainers have more bookings and clubs may hire extra trainers on a shor term basis.

At the level of theoretical abstraction, these two flexibility strategies may appear mutually exclusive. However, they are often combined within the same arrangements, give employees greater control ovirms greater latitude in changing Jones, Lott, \& Mayfield, 1n personal training, both full- and part-time workers the size of the work forments to reflect not only clients' schedules, but their own flexibly schedule appointments parallel careers, demands, and pursuits. Furtheras well, making time for oth pe combined within the same occupation; employthe day, as they perform different job roles and tasks. Such hybrid occupations challenge the presumed unilateral de-skilling and loss of autonomy associated with restrictive flexibility. In combining aspects of restrictive and enabling flexibility, such occupations defy many of the traditional categories of work; for example, highly autonomous, flexible relational skills may be combined with strictly controlled, low-level technical skills. 
lers, they imer satemma of the heart ad scienworker

the gloand cor:es while I experiflexibil$\checkmark$ applies ment in 7). Periir occuty of fitlly chalservices it themtive" or ose size ling and lly flexis deterbe emir wages iible for evident hen pera shorties may le same irk-hour ir, Gadt, hanging workers leir own Furtherimployourse of ipations ted with xibility, xample, tly con-

Personal training is one such hybrid occupation, characterized by a range of skills, autonomy, and flexibility within the varying demands of emotional service work. For example, part-time personal trainers may possess the same range of flexible skills and certifications and enjoy the same level of autonomy as full-time trainers, but without the same employee benefits and job stability that come with full-time status. In personal training, flexibility is less a matter of core or contingent workers, or labor force skill or size, than it is a question of employee autonomy, skills, decision making, and the differential use of flexible strategies to fulfill occupational tasks. The effectiveness and autonomy with which personal trainers perform their job roles is greatly influenced by their use of flexible time schedules, and acquisition, through ongoing training, of flexible specialization.

\section{The Job Roles of Personal Trainers}

A range of job roles emerges out of personal trainers' accounts of their work, both confirming and extending our understanding of emotional service work and flexibility. Like flight attendants, waiters, and receptionists, personal trainers occupy a boundary-spanning position that combines the emotional labor roles of customer service and company representation (Wharton, 1993, 1999). These two responsibilities, managing customers and representing the gym, are marked by varying degrees of flexibility: individual customers require interactive flexibility, while the creation of a consistent company image requires conformity. These job roles do not stand alone, but implicate and require two others: the more diffuse representation of the fitness industry and the entrepreneurial cultivation of both a set of clients and the authority upon which customer service rests.

The service work of personal training thus emerges as a constellation of four job roles, as illustrated in Figure 1: Personal Training at the Intersection of Flexible and Emotional Labor. On the top are those tasks that involve a higher intensity of emotional labor (dealing directly with customers' individual attitudes and emo-

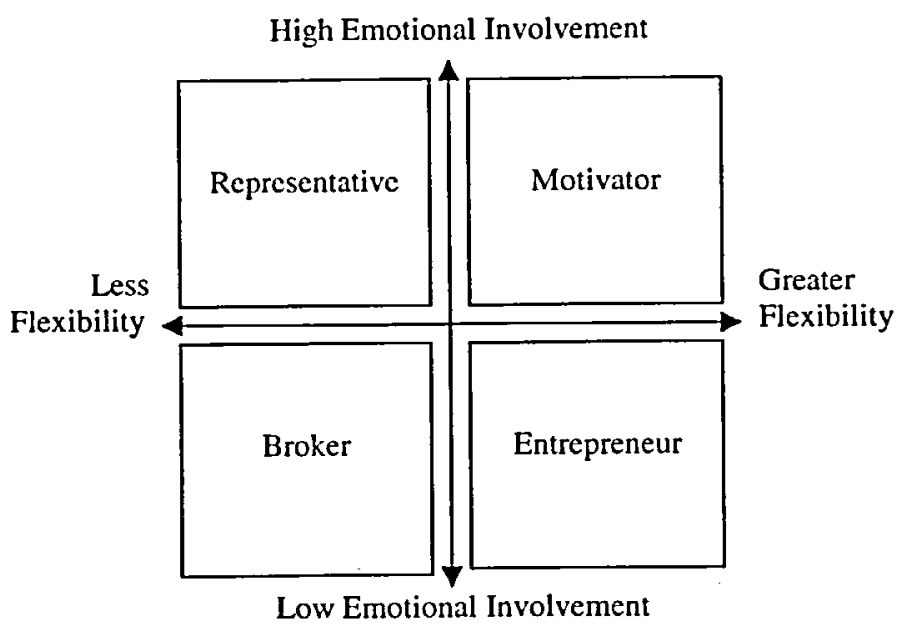

Figure 1 - Personal training at the intersection of flexible and emotional labor. 
tions), while on the left are those tasks that tend to involve less flexibility and autonomy. These divisions capture the different kinds of work associated with personal training: boundary-spanning company delegate (representative), boundary-spanning industry delegate (broker), customer-focused service provider (mo' tivator), and customer-focused authority figure (entrepreneur). The boundary-spanning roles on the left are characterized by less autonomy because they contribute to an overall consistent image and by less flexibility because such work strategies are less relevant to these roles. The customer-focused roles involve both more autonomy, because they must address individual differences between and within clients while creating an authentic service relationship, and more flexibility because strategies such as flexible time and specialization affect how these functions are accomplished.

The job roles are not mutually exclusive, as the expectations and consequences of flexible work strategies and emotional labor practices blur, and at times conflict, between categories. Moreover, what little formal distinction there is between the roles with respect to job training and wage scales far outweighs any distinction made between the times and places assigned to each role. Within the context of any service interaction, a personal trainer is simultaneously performing any and all of these roles. As analytical distinctions, the four roles tease apart how personal trainers are implicated in the larger fitness industry, what skills are explicitly and implicitly required of this kind of work, and to what extent personal trainers control their work conditions. Below, I discuss each role in more detail, drawing illustrations from data gathered during interviews with ten New York City personal trainers and former trainers who now work in club management capacities.

\section{The Role of Representative: Selling the Fitness Club}

As a frontline service provider, the personal trainer acts as a representative-indeed, as the embodiment - of the fitness club. The primary objective of the representative is to establish customer satisfaction with, and loyalty to, the club. While other job roles impact upon customer satisfaction-inferior performance as a motivator, for example, will create a poor impression-it is as representatives that trainers most explicitly forge the link between contentment with the service provider and satisfaction with the company. Trainers can make this link implicitly, through the quality of the personal interaction with the client, or explicitly, through recommendations and endorsements of the club's other goods and services, such as logo t-shirts, aerobics classes, massage therapy sessions, or simply another month's membership.

Among the strategies for establishing an overall corporate image, uniforms are perhaps the clearest visual link between the individual trainer and the fitness club (Solomon, 1998). As an immediate visual cue to the trainer's credentials as a club representative, uniforms not only identify who the personal trainers are, but also let other club members know who is working out with a trainer. Thus, uniforms facilitate a customer's potential interest in status consumption, while creating a visually unified work force. Furthermore, whether working with a client or between appointments, uniforms continue to mark personal trainers, linking their behavior in "off time" to the corporate image. While their paid work ostensibly occurs on a one-to-one basis, personal trainers' role as impression makers is much 
iility and ited with , boundder (moary-spanontribute itrategies th more Id within jility beunctions

d conseat times :re is beighs any ithin the iforming part how $s$ are expersonal e detail, ew York ugement

Iresentasctive of $y$ to, the perforis reprewith the this link rexplicods and , or sim-

iniforms e fitness ials as a are, but Ius, unile creatslient or ng their tensibly is much

more diffuse. In this fashion, trainers' interactions with clients are joined with their behavior alone and with co-workers in the customer's eye to give an overall impression of the club and its professionalism.

In short, the uniform means that a personal trainer is always on duty. This poses two potential drawbacks, one to the job satisfaction of the personal trainer, the other to their successful solicitation of clients. First, the corporate image may impinge upon the autonomy of personal trainers' emotional labor, constraining their control over their relational skills with clients and their "down time" between appointments. While strategies that constrain the service provider's discretionary use of time may impinge upon job satisfaction, the need to maintain a professional demeanor in order to recruit clients is the more pressing concem for trainers. Second, uniforms may create a unified corporate image, but do so in a way that detracts from the very individuality that is being marketed as personal service. Shane, a fitness club program director and personal trainer, commenting upon the role of physique in attracting clients, reveals the informal solution to the dilemma of uniforms:

Exposure on the floor as an exercise trainer is one of the best ways to get a client without making a heavy sell. And when you work out here during your time off, people are looking at you, seeing what kind of body you have. People look really different out of uniform, and so if you're working out in a tank top, and you're really working and getting sweaty, people see that you have a good body. So they put one and one together [and hire you].

Uniforms involve a set of conflicting demands. On the one hand, they create a unified image. On the other, they conceal a trainer's physical assets. Required as part of the role of representative, uniforms are a hindrance to the job requirement of attracting clients; this conflict of roles creates the unofficial need to spend unpaid time in the work place working out.

The role of representative tends to permeate all of the other roles, creating an inherent limit to the autonomy with which trainers perform their other job roles and the license with which they use their time between clients. Personal trainers must balance this general limit on relational flexibility with their clients' demands for personalized service that reflects their individual needs. In general, the creation of a unified image may help to establish customer loyalty, but only if personal trainers negotiate the conflicting expectations of their job roles so that customer service doesn't suffer.

\section{The Role of Broker: Connecting to the Fitness Industry}

Fitness clubs, like companies in general, do not exist in a vacuum, but are part of a larger industry network of associated goods and services. In their frontline service work, personal trainers produce connections between specific fitness activities and the overall consumer fitness culture. Personal trainers thus serve as brokers, initiating or enhancing customers' relationships with fitness and the variety of goods and services that entails. However implicitly, personal trainers are agents of the fitness industry, creating paths of action and meaning that connect the workout session to future and potential purchases of athletic shoes, exercise clothes, nutritional consulting, home exercise equipment, beauty products, exercise videos, fitness-centered vacations, bathroom scales, and so forth. 
Much as the quality of their service is emblematic of the fitness club as a whole, a personal trainer's perceived lifestyle serves as a recommended template for clients. Personal trainers are brokers for a consumer way of life, one which requires specialized equipment, memberships, and accessories in an ongoing project of self-improvement and lifestyle expression. On a more modest scale, the personal trainer brokers future fitness-related purchases by introducing and educating clients about specific types of goods through the course of their workout. The favorable impression that clients receive of particular exercises and equipment creates the heightened potential for subsequent purchases. Such a brokering role has not gone unnoticed in the fitness industry, leaders of which credit personal trainers with facilitating sales of home exercise equipment (Sporting Goods Manufacturers Association, 2000, p. 22). In most cases, personal trainers are neither equipment company representatives nor paid for these peripheral results of their work; as such, the broker role is almost entirely unintended on the part of the trainer. Implicit though it may be, the broker role has real outcomes, including the inadvertent creation of home-based competition to fitness clubs.

Besides their impact on home equipment sales, personal trainers serve as brokers within the fitness club for recruiting and sustaining membership. While membership costs limit prospective members, personal trainers help to broker memberships by reaching out to new member markets. That is, in their ability to individually tailor personal fitness services, personal trainers smooth the introduction to the fitness club for individuals who would otherwise have found gyms to be alien, inscrutable, intimidating places. Women in particular are targeted as a new population for old (stereotypically male) activities, such as boxing, martial arts, or strength training. The popularization and feminization of weight training (Bordo, 1993; Sporting Goods Manufacturers Association, 2000), for example, has extended the potential market for equipment, instruction, and club membership, as many of the personal trainers suggested:

More and more women are weight training. The stereotypes of the past are slowly disappearing. There was an image of the old, professional body builder, using steroids. That's changing, and there are more women using weights. But everyone who works out here is a body builder of sorts. People are building their bodies. (George, fitness club manager and former personal trainer)

In other words, it is not simply that women are participating in body-building, but that body-building has acquired a different mainstream meaning. More fundamental than instructing women in the activity of strength training or weight lifting, personal trainers facilitate the redefinition of what it means to build one's body. Going to the gym, for example, is no longer simply for those who want to "bulk up"; gyms are also places for toning, shaping, weight reduction, socializing, physical therapy, stress reduction, cardiovascular development, and self-improvement. In accommodating a greater variety of motivations, however, personal trainers also reconfirm the prevailing aesthetic definitions of fitness, if not the medical criteria. That is, in their emphases upon their own and clients' bodies, and in their promises of such visible results as improved muscle tone and weight loss, personal trainers reinforce social judgements based on visual criteria. As such, the ways in which trainers perceive fitness - what it means, what it requires-play a defining 
club as a template de which Ig project , the perducating out. The fuipment ring role personal Is Manue neither s of their irt of the Iding the

serve as p. While o broker ability to ntroduc' $\mathrm{ms}$ to be as a new il arts, or (Bordo, has exrship, as

past are $\checkmark$ builder, weights. ople are personal

ly-buildig. More $r$ weight ild one's I want to ializing, mproveral trainmedical 1 in their personal ways in defining

role in how fitness is understood and pursued by clients, in their consumer activities in and outside of the fitness club.

Unlike salespeople, personal trainers accomplish their brokering work through the process of working with the client. As such, customers are less likely to feel pressure to purchase and arguably more receptive to the explicit and implicit suggestions for future purchases. However important to the reproduction of the consumer fitness industry and the fitness club's membership market, the broker role is the one over which personal trainers exercise the least emotional and flexible control and, not coincidentally, the one for which they are least rewarded, if at all. Personal trainers may be frontline boosters for the fitness industry, but they do so as the inadvertent byproduct of the emotional service labor. This suggests that not only are service providers underpaid with respect to their relational skills-as it is technical certifications that continue to largely set wages-but that they also receive no compensation for their indirect work on behalf of the larger industry. As an emotional labor component becomes increasingly important to a vast range of occupations, this undervalued and unpaid aspect of labor is likely to become a growing concern for workers in general.

\section{The Role of Motivator: Establishing a Personal Connection}

In the customer service position, personal trainers perform the most intense emotional labor, combining technical skills (in fitness program design) with relational abilities (in guiding and encouraging clients). The customer service that personal trainers provide is, at bottom, motivational, rather than educational or curative; unlike Physical Education teachers or occupational therapists, for example, personal trainers are motivating partners rather than teachers or doctors. Personal trainers motivate by catering to clients' individual needs, through the cultivation of interpersonal flexibility and personal service relationships. As Tony, a fitness club general manager, said about personal training, "It's a people business. It's health and fitness, but first and foremost it's a customer service position."

The most obvious aspect of the customer service position comes from the client's expectation of being motivated. Personal trainers provide an implicit guarantee that clients actually will work out, a certainty that club membership alone does not provide. Time constraints and competing obligations are among the many obstacles to the improvement of one's level of physical activity. The provision of a motivational service addresses and capitalizes upon one aspect of the paradox of growing gym memberships and lack of improvement in U.S. levels of physical activity (Office of Disease Prevention and Health Promotion, 2000; Sporting Goods Manufacturers Association, 2000; Waters, 2000).

As the materials with which personal trainers work are the variable emotions, motivations, and bodies of clients, they enjoy a high degree of autonomy in establishing how best to work with clients. Motivating clients, therefore, requires a range of skills and aptitudes. Foremost of these skills is interpersonal flexibility, as Rob suggested in his summary of his work as personal trainer:

You become their coach. You are their teacher. You become their coach, their shrink, and their slave driver [laughs]. You have to stay on top of them. If they come in, and they're whining that they're tired and don't want to work out, you have to know how to cope with that. You're dealing with 
people's personalities. They come in, they've had a bad day, their boss yelled at them, and they don't want to work out. You have to know what to do to make sure they have a good work out. I'm their mentor. I'm Yoda [laughs]! I tell them, "You want to be a Jedi? You have to listen to Yoda."

As with emotional labor in general, the style in which personal training services are delivered plays a large role in determining customer satisfaction. Personal trainers must be flexible in their motivational style, moving between such approaches as "mentor," "drill sergeant," and "therapist," depending on the client. The ability to cultivate different styles, and then to effectively intuit the most appropriate style for the client, are part of the relational adaptability of personal training. Such modulation of emotional labor on a case-by-case basis not only requires job autonomy for the personal trainer, but mitigates the potential negative consequences of constraints in other job roles.

The creative versatility required to deal effectively with clients' emotions and personalities results in a blurring of the traditionally gendered modes of service work, in which women were associated with being nice and men with being aggressive (Hochschild, 1983, p. 163). Within the same training session, for example, a trainer may fluctuate between gentler and more assertive modes depending on the client, the particular exercise, or stage of the work out. This is not to suggest that old stereotypes are no longer at work in shaping the emotional labor of men and women, as June remarked:

I try not to get males as clients because I prefer training women. I don't think men take it seriously if you're a woman trainer. I'll be at a bar, hanging out and I'll be talking to some guy. I'll say, "I teach exercise." And they'll be like, "Oh, I'd like to work out with you" [in a sexually suggestive tone]. I'm cautious about that, and that's pretty typical for other female trainers I know. But men can train either men or women. A woman hitting on her male personal trainer is just different.

While the relational flexibility of personal trainers may be hindered by the constraints of corporate image making, women trainers face the additional obstacle of gendered stereotypes.

Central to the trainer's success as a motivator is the personal connection with the client. The personal service interaction caters to the individuality of the client, reinforcing for the client the consumer culture's message that consumption is an avenue for the expression of one's self. Unlike the fitness commodities and services that are external to the buyer, however implicated in expressing an internal sense of self, it is the trainer-client relationship that explicitly creates an internal, personal experience for the client, which then becomes a potential impetus to continue purchasing personal trainer sessions or other services. Thus, personal trainers, like theme park "hosts" and personal shoppers, are at the forefront of shaping and managing consumption of fitness, tourism, and shopping as a lifestyle experience, for those who can afford it.

Establishing a personal service connection, and transforming it into an ongoing service relationship, is not only central to motivating clients, but to ensuring job autonomy and security as well. Companies tend to decrease their intervention in service interactions if employees are regarded as sufficiently motivated to provide high quality service, such as when pay is based on commission or service 
s yelled

to do to aughs]!

services

al trainroaches ability ite style 1 modutonomy of connotions ; of ser$\mathrm{h}$ being for exJepend$s$ not to al labor

't think ying out ey'll be ne]. I'm I know. ale per-

he contacle of

nection $y$ of the imption ties and in interin interpetus to sersonal front of lifestyle

) an onnsuring vention | to proservice

providers work with the same clients over and over (Leidner, 1999). As with other occupations such as hairdressers and child care workers, the service of personal training is greatly shaped by the fact that trainers generally do not work with strangers. The more a personal trainer works with repeat customers, the more stable the personal connection and thus more secure the income.

With a personal and economic stake in the success of ongoing service relationships, personal trainers are thus permitted a high level of autonomy as motivators, in order to generate more authentic customer interactions, and to respond more flexibly to the individual differences of clients. That is, personal trainers can only do their job well if they are given the free reign to make working with a client seem like a personal relationship. Client relationships, however, are not merely the effect of relational skills and/or convincing acting. As June suggested, personal trainers tend to have a high level of personal involvement in their work:

It's how you look, it's enthusiasm, how aware you are, and what you know. That all comes across. It has a lot to do with your spirit. It's something that lends itself to wanting to train in the first place; you can't hate talking, advising, teaching, being gentle, dealing with people.

While a personal trainer is not strictly required to be a "people person," the job role of motivator presents the opportunity for emotional exhaustion. That is, an interest in helping people eases the trainer's task of creating an authentic-seeming personal connection to the client, even in the context of a paid relationship.

At bottom, personal trainers succeed as motivators because of their relational skills, not because of the formal certifications in exercise and physiology that serve as occupational prerequisites. The experience of a frontline service worker, then, is greatly shaped not only by the conditions of work, but by the personality of the worker herself. That is, the self-selection of "people people" for frontline service work creates a good match of occupational demands and individual qualities (Wharton, 1993), creating the optimal conditions for autonomy. Although this realm of autonomy doesn't negate the constraining features of the representative and broker roles, the role of motivator ostensibly wards off the threats of emotional exhaustion and de-skilling, by allowing personal trainers an area of personal engagement with work and compensation in the form of flexibility and selfdetermination.

\section{The Role of Entrepreneur: Cultivating Authority and Clients}

Personal trainers must engage in ongoing self-development and client-development because of the particular organization of training as both boundaryspanning and commission-based work. On the one hand, unless they are recognized and respected as authorities in their field, personal trainers are unable to create the appropriate impression of the fitness club, recommend and endorse other fitness goods and services, or motivate and guide their clients. Thus, in order to fulfill - and juggle - their other job roles, trainers must cultivate a level of authority, unusual for service positions, through ongoing improvement of professional, relational, and physical abilities. On the other hand, even if a personal trainer is employed by a fitness club, he or she isn't guaranteed a stable income because wages depend on the number of client sessions. Thus, trainers must actively recruit service work by developing a regular group of clients. In light of these two 
issues, personal trainers take on the characteristics of entrepreneurs, assuming the responsibility and risk of improving their qualifications and client base in order to develop their personal business.

Personal training falls within a category of professional service work which departs from the traditional, low-skill service stereotype because of its requirement for specialized education and training. As for dental assistants, security guards, or coaches, the extent of specialized education for personal training can range from a few weeks (for basic certification) to a number of years (for related college degrees and continuing training). Professional qualifications give personal trainers a degree of authority that emotional labor alone would not provide, while allowing them to charge more for their specialized services. Such ongoing professional development involves a high degree of flexibility for personal trainers, as it is through their adaptable use of work and leisure time that they may continue their training and certification.

If professional authority is necessary, however, it is not sufficient for success as a personal trainer. As with frontline service workers more generally, a trainer's (fit) physique plays a significant role in a customer's perception of the quality of service. Thus, while certifications and college degrees are the ostensible foundation for professional authority, a personal trainer's physique is equally important to the satisfaction of customers. The personal trainer's physique visually represents his/her personal dedication to fitness, establishing the trainer's authority in the eyes of the client. As June remarked, "You should look at a trainer and say, 'That's the body I want."

Maintaining and improving one's physique, as with the dilemma of uniforms, requires the flexible use of time and often a blurring of work and non-work hours. As Maureen, a fitness club director and former personal trainer, noted, such blurring creates constraints upon the occupation:

I knew I was getting to the end of working only as a personal trainer when I was no longer willing to maintain my own looks in order to maintain my business. I still train a few clients, because I can draw on my experience, my education. I have a lot to offer. But most trainers have to rely on their body, their appearance, to get clients.

The investment of time and energy necessary to sustain such physical self-improvement tends to make personal training a young occupation, while undercutting the professional legitimacy that trainers pursue through certifications.

In their cultivation of authority through professional development and physical self-improvement, personal trainers exercise a high degree of flexibility in their use of time and acquisition of skills. Although flexible, the job role of entrepreneur is not characterized by a high intensity of emotional labor; the trainer's self-improvement occurs outside of the interaction with clients. This is not to suggest that emotional labor strategies are irrelevant to fostering authority, but that in the entrepreneurial role, the motivation for using emotional strategies is more explicitly instrumental. Despite a general absence of formal business training, trainers must acquire an entrepreneurial attitude toward attracting and maintaining client relationships, as Tony, the manager, suggested:

As a trainer, you're always on display. People watch how you train your clients, and they rely on word of mouth. Your client should be your best 
ning the order to $\mathrm{k}$ which require' guards, n range college al trainvhile alprofesers, as it lue their

for sucsally, a $n$ of the tensible ally imvisually authorner and tiforms, $k$ hours. ch blur-

'when I tain my nce, my ir body,

self-imidercutI physiin their preneur self-im'est that e entreplicitly rs must nt relaur best

sales person. They should work for you. And you work to establish that relationship, even outside the gym. You make follow-up phone calls. You send them cards. You make the individual feel good by remembering their name, by making them feel special. That's how you establish a rapport. And that's how you get referrals.

Thus, unlike the emotional labor role of motivator, the entrepreneur places the emphasis upon the instrumental creation of a client base, and not upon the affective satisfaction of the client. In reality, these job roles are intertwined, such that a trainer's motivations may conflict.

The need to recruit clients can thus be a source of tension for personal trainers, who may not relish the business aspect of fitness service. Nevertheless, intrajob conflicts are often reconciled through a personal trainer's own belief in the value of fitness, and in the job satisfaction that comes from their client-motivator relationships. In commenting on how training services are sold, Tony suggested how a trainer's personal fitness convictions act as occupational assets:

Over the last five years, we have asked trainers to be sales people. But you have to explain to them that they're selling their services, their skills. Many of them are uncomfortable when you first suggest it, because they have this image of selling as selling used cars. You have to explain to them that they're selling health and fitness. You're selling something you believe in.

That is, personal trainers overcome the drawbacks of emotional service work because they are "fitness people," as well as "people people." While neither a personal belief in fitness nor highly developed relational skills are the objective basis of wages, a personal trainers' authority status, occupational success, and job satisfaction ultimately rest with his or her personal qualities, which enable a complementary fit between personality and job demands.

\section{Conclusion}

The structure and organization of personal training provides much insight into the intricate ways in which service work, emotional labor, and flexibility combine and conflict in practice. For personal trainers, emotional labor is associated with high job satisfaction because they are allowed great flexibility in their approach to clients, thus establishing a degree of autonomy from the employer in shaping the customer interaction. While job autonomy mitigates the potential pitfalls of emotional labor, the self-selection of individuals with an interest in fitness and relational work also helps moderate the potential alienation involved in selling oneself, the fitness club, and the fitness industry. Moreover, according to most of those interviewed, the blurring of work and leisure time typically is not experienced as an exploitative extension of work responsibilities because exercising and physical improvement are already leisure pursuits for most personal trainers. With high degrees of autonomy and flexibility, and a complementary fit between job demands and service provider personality, personal training emerges as a highly satisfying emotional service occupation.

In its interweaving of emotional labor and flexible work strategies, personal training further refines our understanding of what it means to work in the service economy (Hochschild, 1983; Steinberg \& Figart, 1999; Wharton, 1993, 1999). 
Frontline service occupations such as personal training suggest that there has been a redefinition of job skills. Non-traditional skills and attributes such as physical appearance and personality, and non-wage labor such as working out in one's free time, have come to the fore in determining one's exchange value in the fitness industry labor market. Nevertheless, as much as personality and physical qualities affect occupational success, they continue to be overshadowed by technical certifications in setting the wage rate. Thus, relational skills of service providers continue to be undervalued, even as frontline service becomes increasingly important to the success of businesses and to the broader consumer industries. While the emotional labor component of work may provide rewards in its own right, such benefits will likely prove inadequate; the future may bring growing demands for greater professionalization of, and economic compensation for, relational skills. Such demands are all the more likely given the increasing emphasis upon relational skills in a host of non-service, professional occupations. As students, patients, and citizens are increasingly conceptualized as consumers, the work of educators, doctors, and politicians may increasingly include the management of their consumers' emotions.

The case of personal trainers presented in this paper has underlined the importance for sociologists of sport to bring together the perspectives on labor and consumer culture, in order to understand the varied ways in which work on the body becomes a means of identity-building and target for commercial development (Ewen, 1976, 1999; Falk, 1994; Featherstone, 1982). Health and fitness service occupations require further study in order to better appreciate how the commodification of fit bodies, self-improvement, and the pursuit of health are accomplished through the consumer marketplace. Such occupations provide an insight into the perpetuation and reformulation of the 19th century tenets of personal responsibility for health (Crawford, 1980; Ingham, 1985; White, Young \& Gillett, 1995), and the social use of the body as visual shorthand for one's character (Bordo, 1993; Bourdieu, 1984). Moreover, the nature of emotional service work presents personal trainers with specific responsibilities and obstacles when negotiating the competing claims of health-and appearance-improvement. While the concern for health is often eclipsed by that of appearance, health nevertheless provides motivation, legitimacy, and parallel benefits to the consumption of fitness goods and services.

In general, we must look not only at consumer culture, and its messages of freedom and lifestyle, but at the organization of work as well, in our analyses of the contemporary culture of fitness. With both of these elements in view, we may better understand the ways in which particular occupations help forge the links between narrow fitness activities and broad motivations, be they health-, beauty-, or identity-centered. The emphasis in consumer culture upon expression of one's identity and lifestyle is reinforced in the individualized fitness services of the personal trainer, whose own self-improvement and physique privilege the visible signs of fitness wrought on the outer flesh, rather than the hidden improvements to one's inner state, be it in terms of physical or mental health. In performing their work, personal trainers balance the competing claims of health and appearance, embodying and promoting the notion that the body is not a passive billboard for one's inner self, but the medium through which one carries out and expresses the ongoing process of self-formation. 
las been ohysical ie's free fitness fualities al certiirs coniportant hile the ht, such inds for 1 skills. on relants, paof eduof their

the imbor and on the evelopess serow the lith are vide an of perJung \& charac:e work 1 negoWhile theless of fit-

ages of yses of ve may e links eauty-, f one's he pere signs o one's - work, nbodyr one's ngoing

\section{References}

American Sports Data. (1998). Health club trend report. Retrieved from http://www.ihrsa.org/ industrystats

Balsamo, A. (1994). Feminist bodybuilding. In: S. Birrell \& C.L. Cole (Eds.), Women, sport, and culture (pp.342-52). Champaign, IL: Human Kinetics.

Bordo, S. (1993). Unbearable weight: Feminism, westem culture, and the body. Berkeley, CA: University of California Press.

Bourdieu, P. (1984). Distinction: A social critique of the judgement of taste. London: Routledge and Kegan Paul.

Bourdieu, P. (1990). Programme for a sociology of sport. In: M. Adamson (Trans.), In other words: Essay's towards a reflexive sociology (pp. 156-67). Cambridge, UK: Polity Press.

Braverman, H. (1974). Labor and monopoly capital: The degradation of work in the twentieth century. New York: Monthly Review Press.

Bureau of Labor Statistics. (1999). 1999 National occupational employment and wage estimates. Retrieved from http://www.bls.gov/oeshome.htm

Bureau of Labor Statistics. (2000a). Industry at a glance. Retrieved from http://www.bls.gov/ iag/iaghome.htm

Bureau of Labor Statistics. (2000b). 2000-2001 Occupational outlook handbook. Retrieved from http://www.bls.gov/ocohome.htm

Cole, C.L. (2000). Our new wellness champions. Journal of Sport and Social Issues, 24, 91-5.

Crawford, R. (1980). Healthism and the medicalization of everyday life. Intemational Joumal of Health Services, 10, 365-88.

Donnelly, P., \& Young K. (1988). The construction and confirmation of identity in sport subcultures. Sociology of Sport Joumal, 5, 223-40.

Drury, S.J. (1983, November 21). Wellness can be the solution to rising health care costs. Business Insurance, 17, p. 25.

Ewen, S. (1976). Captains of consciousness: Advertising and the social roots of the consumer culture. New York: McGraw-Hill.

Ewen, S. (1999). All consuming images: The politics of style in contemporary culture (revised ed.). New York: Basic Books.

Falk, P. (1994). The consuming body. London: Sage.

Featherstone, M. (1982). The body in consumer culture. Theory, Culture and Society, 2, 1833.

Featherstone, M. (1991). Consumer culture and postmodernism. London: Sage.

Field, S. (2000). The unofficial guide to hot careers. Foster City, CA: IDG Books Worldwide, Inc.

Fine, G.A. (1987). With the boys: Little league baseball and preadolescent culture. Chicago: University of Chicago Press.

Gabor, M., Gadt, J., Jones, M., Lott, P., \& Mayfield, I. (Eds.). (1999). Report on the American workforce 1999. Washington, DC: U.S. Department of Labor.

Gibson, R.F. (1974, October 21). Join a health club? Who? Me? Industry Week, 183, p. 41.

Gilmore, C.P. (1977, March 27). Taking exercise to heart. The New York Times, p. F38.

Glassner, B. (1989). Fitness and the postmodern self. Journal of Health and Social Behavior, 30, 80-91.

Goldman, J., \& Kennedy, L. (1983). The New York urban athlete: Sport, fitness, and fun in the big apple. New York: Simon and Schuster, Inc. 
Green, H. (1986). Fit for America: Health, fitmess, sport and American society. New York: Pantheon Books.

Gruneau, R. (1997). The politics and ideology of active living in historical perspective. In: J.E. Curtis \& S.J. Russell (Eds.), Physical activity in human experience: Interdisciplinary perspectives (pp. 191-228). Champaign, IL: Human Kinetics.

Helliker, K. (1999, February 25). They left professions for a true calling as personal trainers. Wall Street Joumal, pp. A1, A8.

Hochschild, A.R. (1983). The managed heart: Commercialization of human feeling. Berkeley, CA: University of California Press.

Ingham, A.G. (1985). From public issue to personal trouble: Well-being and the fiscal crsis of the state. Sociology of Sport Joumal, 2, 43-55.

Kaye, D. (1977, March 27). Spring shape-up guide. The New York Times, p. F44.

Leidner, R. (1999). Emotional labor in service work. The Ammals of the American Academy of Political Social Science, 561, 81-95.

Lloyd, M. (1996). Feminism, aerobics and the politics of the body. Body and Society, 2(2), 79-98.

MacNeill, M. (1994). Active women, media representations, and ideology. In: S. Birrell \& C.L. Cole (Eds.), Women, sport, and culture (pp. 273-87). Champaign, IL: Human Kinetics.

Maguire, J., \& Mansfield, L. (1998). "No-body's perfect": Women, aerobics, and the body beautiful. Sociology of Sport Journal, 15, 109-37.

Mrozek, D.J. (1989). Sport in American life: From national health to personal fulfillment, 1890-1940. In: K. Grover(Ed.), Fitness in American culture: Images of health, sport, and the body, 1830-1940 (pp. 18-46). Amherst, MA: University of Massachusetts Press.

O'Brien, T. (1997). The personal trainer's handbook. Champaign, IL: Human Kinetics.

Office of Disease Prevention and Health Promotion. (2000). Healthy people 2010. Washington, DC: U.S. Department of Health and Human Services.

Peiss, K. (1998). Hope in a jar: The making of America's beauty culture. New York: Henry Holt and Company.

Pine, B.J., II, \& Gilmore, J.H. (1998). Welcome to the experience economy. Harnard Business Review, July-August, 97-105.

Piore, M., \& Sabel, C. (1984). The second institutional divide: Possibilities for prosperity. New York: Basic Books.

Pristin, T. (1998, August 16). Health clubs consolidate as membership grows. The New York Tìmes, p. A35.

Rader, B.G. (1997). The quest for self-sufficiency and the new strenuosity. In: S.W. Pope (Ed.), The new American sport history: Recent approaches and perspectives (pp. 402-16). Urbana, IL: University of Illinois Press.

Rapp, J.C., Campbell, K., Thompson, W.R., \& Terbizan, D. (1999). Professional preparation of personal trainers. The Journal of Physical Education, Recreation and Dance, 70, 54-6.

Riess, S.A. (1989). City games: The evolution of American urban socicty and the rise of sports. Urbana, IL: University of Illinois Press.

Roberts, S.O. (1996). The business of personal training. Champaign, IL: Human Kinetics. Sage, G.H. (1998). The political economy of fitness in the United States. In: K. Volkwein (Ed.), Fitness as cultural phenomenon (pp. 111-30). New York: Waxmann Munster.

Schwartz, H. (1986). Never satisfied: A cultural history of diets, fantasies, and fat. New York: Anchor Books. 
Slater, D. (1997). Consumer culture and modemity. Cambridge: Polity Press.

Smith, V. (1994). Institutionalizing flexibility in a service firm: Multiple contingencies and hidden hierarchies. Work and Occupations, 21, 284-307.

Smith, V. (1997). New forms of work organization. Annual Review of Sociology, 23, 31539.

Solomon, M.R. (1998). Dressing for the part: The role of costume in the staging of the servicescape. In: J.F. Sherry, Jr. (Ed.), Servicescapes: The concept of place in contemporary markets (pp. 81-107). Lincolnwood, IL: NTC Business Books.

Sporting Goods Manufacturers Association. (2000). Tracking the fitness movement: 2000. North Palm Beach, FL: Author.

Stearns, P. (1997). Fat history: Bodies and beauty in the modern west. New York: New York University Press.

Steinberg, R.J., \& Figart, D.M. 1999. Emotional labor since The Managed Heart. The Annals of the American Academy of Political Social Science, 561, 926.

Susman, W. (1979). "Personality" and the making of twentieth-century culture. In: J. Higham \& P.K. Conkin (Eds.), New directions in American intellectual history (pp. 212-26). Baltimore: Johns Hopkins University Press.

Taylor, A. (1969, May 26). Where everyone swings on the rings. The New York Times, p. 50.

Taylor, A. (1972, March 24). From shimmying to standing on your head: Ways of shaping up. The New York Times, p. 36.

Vanderbilt, T. (1998). The sneaker book: Anatomy of an industry and an icon. New York: The New Press.

Waters, C.R. (2000, December). Profiles of success: Are health clubs prospering because of a good economy...or because they're doing business better? CBI Magazine, 48-53.

Watkins, E. (1993). Throwaways: Work culture and consumer education. Stanford: Stanford University Press.

Wernick. A. (1991). Promotional culture: Advertising, ideology and symbolic expression. London: Sage.

Wharton, A.S. (1993). The affective consequences of service work: Managing emotions on the Job. Work and Occupations, 20, 205-32.

Wharton, A.S. (1999). The psychosocial consequences of emotional labor. The Annals of the American Academy of Political Social Science, 561, 158-76.

White, P., Young, K., \& Gillett, J. (1995). Bodywork as a moral imperative: Some critical notes on health and fitness. Society and Leisure, 18, 159-82.

Whorton, J.C. (1982). Crusaders for fimess: The history of American health reformers. Princeton, NJ: Princeton University Press.

Young, K. (1991). Violence in the workplace of professional sport from victimological and cultural studies perspectives. Intentational Review for the Sociology of Sport, 26, 312.

Young, K. (1993). Violence, risk, and liability in male sports culture. Sociology of Sport Joumal, 10, 373-96.

\section{Notes}

'The specific scale of personal training is difficult to establish because of a lack of industry statistics. However, the Bureau of Labor Statistics (1999) records just over 127,000 fitness trainers and aerobics instructors, approximately $5 \%$ of all personal care service occupations. According to the Website for the overall fitness club industry body, The International Health, Racquet and Sportsclub Association (http://www.ihrsa.org), approximately 
half of their member fitness clubs consider personal training to be the most profitable of their range of programs and services.

${ }^{2}$ The sample of 10 interviewees was drawn from a range of types of clubs and included current personal trainers and former trainers now employed within club management. Participants ranged in age from 25 to 45 with an average age of $33 ; 2$ were Black and 8 white; and 6 were men and 4 women. Interviews lasted approximately 45 min and focused upon the major themes of job responsibilities, educational and occupational backgrounds, and career paths for personal trainers. Managers were asked about their experience as trainers, as well as the general details of the personal training program at their club.

${ }^{3}$ In general, health services are one of three fastest growing sectors in the entire service industry, itself the fastest growing part of the U.S. economy. Specifically, sport and physical training instructors are among the 10 fastest growing jobs for its educational requirement (Bureau of Labor Statistics, 2000b; see also Field, 2000, p. 204).

${ }^{4}$ Examples of such organizations include the American Council on Exercise (in the U.S.), the National Register of Personal Fitness Trainers (in the U.K.), and the Canadian Alliance of Professional Personal Fitness Trainers (in Canada).

${ }^{5}$ Names of the interview participants have been changed.

${ }^{6}$ The acronyms stand for Young Urban Professionals and Black Urban Professionals, referring to young, well-paid professionals with affluent lifestyles.

${ }^{7}$ Of the approximately 30 million health club members in the U.S., $39 \%$ have an annual income of more than $\$ 75,000 ; 26 \%$ make between $\$ 50-\$ 75,000 ; 23 \%$ are between $\$ 25-\$ 50,000$, and $12 \%$ make less than $\$ 25,000$ (American Sports Data, 1998).

${ }^{8}$ According to the Bureau of Labor Statistics, fitness trainers and aerobics instructors have a median hourly wage of about $\$ 11$ and a median annual income of just over $\$ 22,000$. However, within the occupation, $10 \%$ annually make less than $\$ 13,000$, while $10 \%$ make more than $\$ 48,000$. In comparison with other personal care and service occupations, fitness trainers fall between manicurists and pedicurists, who make approximately $\$ 14,000$ annually, and flight attendants, who make approximately $\$ 43,000$ (Bureau of Labor Statistics, 1999).

\section{Acknowledgments}

The author thanks the Social Sciences and Humanities Research Council of Canada and The Graduate Center for their financial support. Thanks are also due to the anonymous reviewers for their thoughtful and detailed comments on an earlier version of this paper. 